\title{
Phytochemical analysis and antibacterial activity of Cleome gynandra L. Stem and Leaf extracts
}

\author{
Abhilasha. $\mathbf{N}^{1}$, Beligiriranga. $\mathrm{V}^{2}$, Meghashree. A. $\mathbf{M}^{3}$ \\ ${ }^{1}$ PG Student of Botany, JSS college of Arts, Commerce and science, Mysuru, Karnataka \\ ${ }^{2}$ HOD, PG Department of Botany, JSS college of Arts, Commerce and science, Mysuru, Karnataka \\ ${ }^{3}$ Assistant Professor, PG Department of Botany, JSS college of Arts, Commerce and science, Mysuru, Karnataka
}

\begin{abstract}
The crude extraction of Cleome gynandra L. leaf and stem obtained in different solvents like methanol, ethanol and water was subjected to preliminary phytochemical analysis and the antibacterial screening against the gramnegative bacteria. Phytochemical study of both stem and leaf extracts shows the presence of secondary metabolites like Alkaloid, Cardiac glycosides, Flavonoids, Phlobatannins, Amino acids and Proteins which were predominantly present in all tested solvent extracts, followed by Saponins were present only in the methanol and water extract of both stem and leaf. Among all the three tested solvent of stem and leaf extract shows the various degree of significant antibacterial activity against Escherichia coli and Pseudomonas aeruginosa. Methanol extract of leaf shows the maximum inhibitory activity against E. coli and ethanol extract of both stem and leaf shows the similar inhibitory action against both tested bacteria. Water extract of stem and leaf shows the minimum inhibition with reference to the standard (Chloramphenicol).
\end{abstract}

Keywords- Phytochemical analysis, Antibacterial activity, Cleome gynandra L.

\section{INTRODUCTION}

Phytochemicals are the chemicals which are present in the plants naturally; in recent years these phytochemicals have become more popular because of its innumerable medicinal uses. Unlike synthetic chemicals, these phytochemicals do not have any side effects, because they are considered as a human friendly and can cure lots of diseases and disorders [1]. From the classical time across the world people are exploring plants to obtain new drugs. Almost 80 to $90 \%$ people are depended on plants for their treatment of diseases. Most of the medicinal plants are used in traditional system like Unani, Ayurveda, Homeopathy and Siddha [2]. Plants are the treasure homestead of the prospective drugs. These drugs are known for their effectiveness, less expensive, safety and efficiency. Plants are capable to produce some compounds which are having the ability to show activity against various pathogenic bacteria. Most of the phytochemicals belongs to the different chemical classes which has the capability to inhibit all type of microorganism in vitro [3]. But now there are challenges to obtain resistance to bacterial pathogens with available drugs, therefore analysis of antibacterial activity is the matter of concern to develop drugs to various bacterial diseases [4].

Cleome gynandra L. is an herb belong to the family Cleomaceae, earlier it was placed in Capparaceae, under the division Angiosperm, distributed in Asia and African countries. It is having a long taproot with secondary roots and root hairs and aerial stem with glandular hairs. Leaves digitately palmate, having 5 leaflets with long petiole and arranged in alternative manner. Leaflets are having dentate margin with oval or elliptical in shape. Terminal inflorescence which denotes raceme bearing flowers with long pedicel arises singly in the axis of small leafy bract. Basically, flowers are white in colour, tetramerous having 6 stamens with long pedicel arises from elongated receptacle [5].

\section{EXPERIMENTAL METHODS OR METHODOLOGY}

\subsection{Collection of plant materials}

Fresh aerial parts of the Cleome gynandra L. were collected from the Hulimavu gudda which is located in Nanjangudu taluk, Mysuru district. It lies in 12.119708 Latitude and 76.682792 Longitude. The collected plant material was taxonomically identified and authenticated by the taxonomist and also confirmed using Gamble flora. Herbarium was submitted to the PG Department of Botany, JSS college of Arts, commerce and science, Ooty road, Mysuru. Collected plant parts washed thoroughly with the running tap water to remove the dust particles, then again wash with distilled water [6]. After washing leaves and stem part were separated, the plant material was shade dried. After completion of drying, the plant materials were ground well using mechanical blender into fine powder and transferred into airtight containers with proper labelling for future use [7]. 


\section{International Advanced Research Journal in Science, Engineering and Technology}

Vol. 8, Issue 12, December 2021

DOI: $10.17148 /$ IARJSET.2021.81227

\subsection{Preparation of plant extract \\ 2.2.1 Cold Extraction Method}

Polar solvents like methanol, ethanol and water were selected as solvent for the extraction. $50 \mathrm{~g}$ of fine powdered leaves and stem sample is soaked in $150 \mathrm{ml}$ of methanol, ethanol and water separately in beaker for 72 hours. These soaked materials were stirred frequently to facilitate better extraction. Then the mixture is filtered using Muslin cloth and then filtrate was again filtered with Whatman No. 1 filter paper, methanol and ethanol extracts were evaporated to remove the solvent and air dried, then transferred into vials, labelled to keep for further use. Whereas water extract was directly stored at $4{ }^{\circ} \mathrm{C}$ for the future use with the proper labelling [8].

\subsubsection{Phytochemical Screening}

Preliminary phytochemical analysis carried out using the standard methods [9].

(a) Test for Alkaloids (Wagner's reagent): A fraction of extract was treated with 3-5drops of Wagner's reagent and observed for the formation of reddish-brown precipitate or colouration.

(b) Test for Carbohydrates (Molisch's test): Few drops of Molisch's reagent were added to $2 \mathrm{ml}$ of extracts. This was followed by addition of $2 \mathrm{ml}$ of conc. $\mathrm{H}_{2} \mathrm{SO}_{4}$ down the side of the test tube. The mixture was then allowed to stand for two-three minutes. Formation of a red or dull violet colour at the interphase of the two layers was a positive test.

(c) Test for Cardiac glycosides (Keller Kelliani's test): $5 \mathrm{ml}$ of each extract was treated with $2 \mathrm{ml}$ of glacial acetic acid in a test tube and a drop of ferric chloride solution was added to it. This was carefully under layer with $1 \mathrm{ml}$ concentrated sulphuric acid. A brown or violet ring may appear below the ring while in the acetic acid layer, a greenish ring may form. (d) Test for Flavonoids (Alkaline reagent test): $2 \mathrm{ml}$ of extracts was treated with few drops of $20 \%$ sodium hydroxide solution. Formation of intense yellow colour, which becomes colourless on addition of dilute hydrochloric acid, indicates the presence of flavonoids.

(e) Test for Phenols (Ferric chloride test): A fraction of the extracts was treated with aqueous 5\% ferric chloride and observed for formation of deep blue or black colour.

(f) Test for Phlobatannins (Precipitate test): Deposition of a red precipitate when $2 \mathrm{ml}$ of extract was boiled with $1 \mathrm{ml}$ of $1 \%$ aqueous hydrochloric acid was taken as evidence for the presence of Phlobatannins.

(g) Test for Saponins (Foam test): To $2 \mathrm{ml}$ of extract was added $6 \mathrm{ml}$ of water in a test tube. The mixture was shaken vigorously and observed for the formation of persistent foam that confirms the presence of saponins.

(h) Test for Sterols (Liebermann-Burchard test): $1 \mathrm{ml}$ of extract was treated with few drops of chloroform, acetic anhydride and conc. $\mathrm{H}_{2} \mathrm{SO}_{4}$ and observed for the formation of dark pink or red colour.

(i) Test for Tannins (Braymer's test): $2 \mathrm{ml}$ of extract was treated with $10 \%$ alcoholic ferric chloride solution and observed for formation of blue or greenish colour solution.

(j) Test for Terpenoids (Salkowski's test): $1 \mathrm{ml}$ of chloroform was added to $2 \mathrm{ml}$ of each extract followed by a few drops of concentrated sulphuric acid. A reddish-brown precipitate produced immediately indicated the presence of terpenoids.

(k) Test for Quinones: A small amount of extract was treated with concentrated HCL and observed for the formation of yellow precipitate or colouration.

\subsection{Anti- Bacterial Activity}

Bacterial cultures of Escherichia coli, Pseudomonas aeruginosa were collected from the PG Department of Biotechnology and PG Department of Botany, JSS college of Arts, Commerce and Science. Ooty road. Mysuru. 28 gm of nutrient agar (Hi media) was dissolved in $1000 \mathrm{ml}$ of distilled water, homogenised and sterilized.

For the antibacterial activity agar well, diffusion method was used. Nutrient agar is poured to the sterile Petri plates, allowed it to solidify. After that $100 \mu \mathrm{L}$ of bacterial sample of E. coli and P. aeruginosa were spread separately then makes well on the surface of agar plates with the help of cork- borer aseptically in front of spirit lamp and in laminar airflow to avoid the cross contamination of other bacteria. Then fill the wells with the $50 \mu \mathrm{L}$ plant extract of different solution for the both plates. After the inoculation wrap the Petri plates with the clinging wrap to avoid contamination then keep the plates at bacterial incubator for 24 hours at $34{ }^{\circ} \mathrm{C}$. Then observed for the clear zone of antibacterial activity of the different solvent extracts against the bacteria. Measure the zone of inhibition and compare the antibacterial activity of the different extract with the standard chloramphenicol [10]. And activity index was calculated using following formula,

Activity index $(\mathrm{AI})=\frac{\text { Inhibition zone of the sample }}{\text { Inhibition zone of the standard }}$

\section{RESULTS AND DISCUSSION}

Preliminary phytochemical screening of the powdered leaf and stem of the C. gynandra L. revealed the following compounds like Alkaloids, Cardiac glycosides, Flavonoids, Phlobatannins, Amino acids, Proteins and 


\section{International Advanced Research Journal in Science, Engineering and Technology}

Vol. 8, Issue 12, December 2021

DOI: $10.17148 /$ IARJSET.2021.81227

Saponins (only in methanol and water extracts), followed by Carbohydrate, Phenols, Sterols, Tannins, Terpenoids, Quinones and Anthroquinones are absent with different solvents like methanol, ethanol and water.

The antibacterial properties of C. gynandra L. plant were analysed by using three solvents (methanol, ethanol and water). The plant shows the antibacterial activity against the pathogenic bacteria such as P. aeruginosa and E. coli revealed that the methanol and ethanol extract of C. gynandra L. possessed broad spectrum of antibacterial activity compared to the water extract. The diameter of inhibition zones produced by the three different extract of C. gynandra L. against the pathogenic bacteria like P. aeruginosa and E. coli, showed a good inhibition. Methanol extraction of leaf shows the maximum inhibitory concentration against the E. coli and ethanol extraction of both stem and leaf shows the similar inhibitory action against the both tested bacteria (E. coli and P. aeruginosa). Water extraction of stem and leaf shows the minimum inhibitory concentration against the P. aeruginosa and E. coli respectively.

Table 1: Phytochemicals tests for Cleome gynandra $L$.

\begin{tabular}{|c|c|c|c|c|c|c|}
\hline \multirow[t]{2}{*}{ TEST } & \multicolumn{3}{|l|}{ STEM } & \multicolumn{3}{|l|}{ LEAF } \\
\hline & Methanol & Ethanol & Water & Methanol & Ethanol & Water \\
\hline Alkaloids & + & + & + & + & + & + \\
\hline Carbohydrate & - & - & - & - & - & - \\
\hline Cardiac glycosides & + & + & + & + & + & + \\
\hline Flavonoids & + & + & + & + & + & + \\
\hline Phenols & - & - & - & - & - & - \\
\hline Phlobatannins & + & + & + & + & + & + \\
\hline Amino acids & + & + & + & + & + & + \\
\hline Protein & + & + & + & + & + & + \\
\hline Sterols & - & - & - & - & - & - \\
\hline Saponins & + & - & + & + & - & + \\
\hline Tannins & - & - & - & - & - & - \\
\hline Terpenoids & - & - & - & - & - & - \\
\hline Quinones & - & - & - & - & - & - \\
\hline Anthroquinones & - & - & - & - & - & - \\
\hline
\end{tabular}

NOTE: '+' indicates presence of phytochemical, '-' indicates absence of phytochemical.

\section{Antibacterial activity}

The plant Cleome gynandra L. shows the maximum Anti-bacterial activity with the Escherichia coli than Pseudomonas aeruginosa.

Table 2: Zone of inhibition $(\mathrm{mm})$ of various plant extracts against tested bacterial pathogen at $1 \mathrm{mg} / \mathrm{ml}$ concentration. NOTE: Values are means of three independent replicates.

\begin{tabular}{|l|l|l||l|l|}
\hline \multirow{2}{*}{ COMPONENTS } & \multicolumn{4}{|l|}{ ZONE OF INHIBITION (in mm) } \\
\cline { 2 - 5 } & \multicolumn{2}{|l|}{ LEAF } & \multicolumn{2}{l|}{ STEM } \\
\cline { 2 - 5 } & P. aeruginosa & E. coli & P. aeruginosa & E. coli \\
\hline Standard (Chloramphenicol) & 0.21 & 0.12 & 0.21 & 0.26 \\
\hline Methanol & 0.14 & 0.06 & 0.18 & 0.23 \\
\hline Ethanol & 0.16 & 0.08 & 0.12 & 0.16 \\
\hline Water & 0.08 & 0.07 & 0.03 & 0.09 \\
\hline Control (Distilled water) & 0 & 0 & 0 & 0 \\
\hline
\end{tabular}


International Advanced Research Journal in Science, Engineering and Technology

Vol. 8, Issue 12, December 2021

DOI: $10.17148 /$ IARJSET.2021.81227

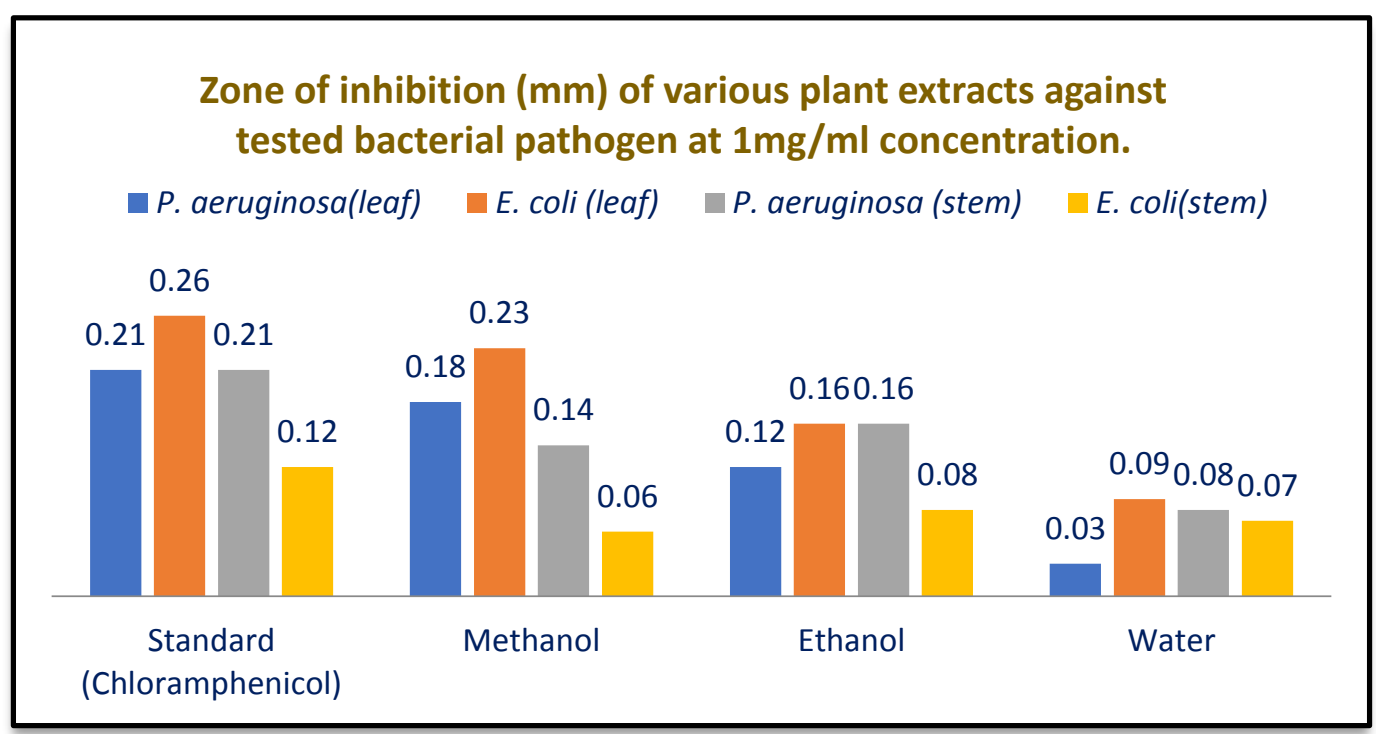

Figure 1: Zone of inhibition (mm) of various plant extract against tested bacterial pathogen.

\section{Activity index}

Table 3: Activity index of inhibition $(\mathrm{mm})$ of various plant extract against tested bacterial pathogen at $1 \mathrm{mg} / \mathrm{ml}$ concentration.

\begin{tabular}{|l|l|l|l|l|}
\hline \multirow{2}{*}{ COMPONENTS } & \multicolumn{2}{|l|}{ STEM } & \multicolumn{2}{l|}{ LEAF } \\
\cline { 2 - 5 } & P. aeruginosa & E. coli & P. aeruginosa & E. coli \\
\hline Methanol & 0.85 & 0.88 & 0.66 & 0.50 \\
\hline Ethanol & 0.57 & 0.61 & 0.76 & 0.66 \\
\hline Water & 0.14 & 0.34 & 0.38 & 0.58 \\
\hline
\end{tabular}

\section{ACTIVITY INDEX}

$\square$ P. aeruginosa (leaf) $\square$ E. coli (leaf) $\square P$. aeruginosa $($ stem $) \square$ E. coli (stem) $0.85^{0.88}$

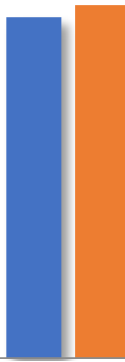

Methanol

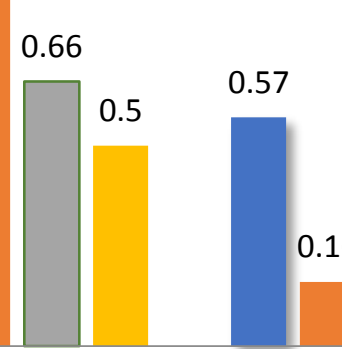

Ethanol
0.76
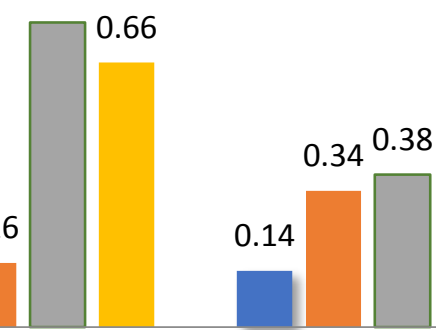

Water

Figure 2: Activity index of inhibition (mm) of various plant extract against tested bacterial pathogen 


\title{
International Advanced Research Journal in Science, Engineering and Technology
}

\author{
Vol. 8, Issue 12, December 2021
}

DOI: $10.17148 /$ IARJSET.2021.81227

\section{CONCLUSION}

As per the research phytochemical studies can provide a solution to the people seeking for better therapeutic medicine from natural source which is supposed to be more efficient with less or no side effects when compared to the commonly used synthetic agents. C. gynandra L. is used as traditional medicines to treat various human disorders. C. gynandra L. is a rich source of phytochemicals are tannins, protein, amino acids, cardiac glycosides, saponins, alkaloids and flavonoids have been used as antibacterial agents. Flavonoid is belonging to the secondary metabolites can protect the human body from the oxidative stress which may cause many diseases, including cancer, cardiovascular problems and ageing. Cleome gynandra L. can be utilized as an alternative source for useful drugs.

\section{REFERENCES}

1. Banu K. S. and Cathrine L. "General Techniques Involved in Phytochemical Analysis." International Journal of Advanced Research in Chemical Science, pp. 25-32. 2015.

2. Visweswari G., Christopher R. and Rajendra, W. "Phytochemical screening of active secondary metabolites present in Withania somnifera root: Role in traditional medicine." International Journal of Pharmaceutical Sciences and Research, pp. 2770-2776. 2015.

3. Yadaw R. N. S. and Agarwala M. "Phytochemical analysis of some medicinal plants." Journal of Phytology, pp. 10-14. 2011.

4. Sasidharan S., Chen, Y., Saravanan, D., Sundram, K. M. and Latha, L. Y. "Extraction, isolation and characterization of bioactive compounds from plants extracts." African Journal of Traditional, Complementary and Alternative Medicines, pp. 1-10. 2011.

5. Chweya J. A. and Mnzava N. A. “Cat's whiskers: Cleome gynandra L.” International Plant Genetic Resources Institute (IPGRI), pp. 54-52. 1997.

6. Banu K. S. and Cathrine L. "General Techniques Involved in Phytochemical Analysis.” International Journal of Advanced Research in Chemical Science, pp. 25-32. 2015.

7. Yadaw R. N. S. and Agarwala M. "Phytochemical analysis of some medicinal plants." Journal of Phytology, pp. 10-14. 2011.

8. Darshan Dharajiya1, Nalin Pagi, Hitesh Jasani and Payal Patel. "Antimicrobial Activity and Phytochemical Screening of Aloe vera (Aloe barbadensis Miller).” International Journal of Current Microbiology and Applied Sciences, pp. 2152-2162. 2017.

9. Ugochukwu S. C., Uche A. and Ifeanyi O. "Preliminary phytochemical screening of different solvent extracts of stem bark and roots of Dennetia tripetala." Asian Journal of Plant Science and Research, pp. 10-13. 2013.

10. Sharma J. and Kumar P. "Comparative study of antimicrobial activity and phytochemical screening of serial extraction from leaves and fruit of Aegle marmelos and Carica papaya.” International Journal of Pharmacy and Pharmaceutical Sciences, Pp. 119-123. 2017. 